\title{
Lactic Acid Bacteria From Saltwater Fish Samples: Probiotic Potential Characterization and Clustering Using Unsupervised Algorithms
}

Atefeh Mazlomi

Tabriz University

Bahman Panahi

Agricultural Research, Education and Extension Organization (AREEO)

Yousef Nami ( $\nabla$ yousefnami2010@gmail.com)

Agricultural Research, Education and Extension Organization (AREEO)

\section{Research Article}

Keywords: Saltwater fish, Lactic acid bacteria, Probiotics, Unsupervised algorithms

Posted Date: December 8th, 2021

DOI: https://doi.org/10.21203/rs.3.rs-1106400/v1

License: () (i) This work is licensed under a Creative Commons Attribution 4.0 International License. Read Full License 


\begin{abstract}
This research aimed to isolate lactic acid bacteria (LAB) from the bowl of saltwater fish to assess their probiotic properties. Nineteen isolates of LAB including Lactobacillus plantarum, Lactobacillus acidophilus, Lactobacillus fermentum, Lactococcus lactis, Enterococcus hirae, Enterococcus lactis, Pediococcus pentosaceus, Pediococcus acidilactici, and Pediococcus lolli were recognized using molecular tools. All the isolates survived in the simulated conditions of the Gl tract. Auto-aggregation ranged from $01.3 \pm 0.5 \%$ to $82.6 \pm 1.4 \%$ and hydrophobicity with toluene ranged from $3.7 \pm 1.6 \%$ to $69.4 \pm 1.3 \%$, while the range of hydrophobicity with xylene was from $02.2 \pm 1.6 \%$ to $56.4 \pm 2.1 \%$. All the isolates of lactobacilli, pediococci, enterococci, and lactococci indicated variable sensitivity and resistance towards clinical antibiotics. Non-neutralized cell free supernatant of isolates F12 and F15 showed antimicrobial activity against all the 8 evaluated enteric pathogens. Cluster analysis of identified potential probiotic bacteria based on heat-map and PCA methods also highlighted the priority of isolates F3, F7, F12, and F15 as bio-control agents in fishery industry. The findings of this study may essentially contribute to the understanding of the probiotic potential of LAB in saltwater fish, in order to access their probiotic characterization for use as biocontrol in fishery.
\end{abstract}

\title{
1. Introduction
}

Aquaculture is a significant food sector for a growing global human people and has quickly extended due to intensified culture methods ${ }^{1}$. Nonetheless, the expansion, diversity and enhancement of aquaculture have increased the frequency of disease epidemics in recent decades ${ }^{2}$, with bacteria being the largest pathogen in aquaculture and causing mass mortality in aquaculture ${ }^{3}$. Handwork of intestinal biota utilizing dietary supplements is an inventive confronts to correct the improvement capability and intestine security of lentic life forms ${ }^{4}$. At the choice of suitable probiotics is exceptionally noteworthy since of improper microbes may cause awkwardness within the creature intestine and adversely penetration on immunomodulation, adversarial movement against pathogens, parcel of the colonialism request and digestibility of cooking ${ }^{5}$.

The generic probiotic microorganism should able to increase and colonize in the host gut. In aquaculture manufacture, the joinery probiotics used in earthly animals have indifferent and failure to colonize the gut of the host organism ${ }^{6}$. Proposed connections between modulation in the gut microbiota with physiology and illness have headed increased regard of the scientific society eminent to detailed researches on the microbial variety in fish ${ }^{7}$. The bowel is one of the main putridity ways in fish because they are evermore in sincare contact to their perimeter, water, and are sequentially exposed to bacteria containing pathogens. The bowel microbiota of fish plays a significant impress in mediating and agitating host gastrointestinal extension, given digestive subordinate, maintaining mucosal forbearance, fiery the hostess immunoresponse and providing a level of conservation versus gastric infections ${ }^{8}$. In this work, bacteria colonized in the bowel of fish were isolated and characterized as potential probiotic bacteria. They were utilized as biocontrol against some major fishery pathogens.

\section{Materials And Methods}

\subsection{LAB strains and culture condition}

A total of 15 fresh edible saltwater fish samples were purchased from retail fish shops in Qeshm Island (located in Persian Gulf, South of Iran). The samples were brought on ice to the laboratory of Gol Sahand Khosrou Science-based Company. To isolate LAB from the intestinal contents of the fish samples, $5 \mathrm{~g}$ of intestinal contents was inoculated into $50 \mathrm{~mL}$ of de Man Rogosa and Sharpe (MRS, Merck, Darmstadt, Germany) broth containing $25 \mathrm{~g} / \mathrm{L}$ NaCl and incubated at $37^{\circ} \mathrm{C}$ for $3-7$ days. After the incubation time, all cultures were streaked separately on MRS agar plate and incubated anaerobically at $37^{\circ} \mathrm{C}$ for $3-7$ days in anaerobic jars containing anaerobic gas generation kits. Colonies with different morphology were isolated from the incubated MRS agar plates. After morphological and biochemical assays (Gram-staining, catalase activity, cell morphology, and spore formation), Gram-positive and catalase-negative rodsand cocci-shaped bacteria were identified as LAB isolates.

\subsection{Acid and bile resistance}

The MRS broth with pepsin enzyme $(3 \mathrm{mg} / \mathrm{mL})$ was utilized as a medium to assess acid resistance. The $\mathrm{pH}$ of broth was adjusted to $2.5 \mathrm{with} 1.0 \mathrm{~N} \mathrm{HCl}$ and broth ( $\mathrm{pH}$ 7.0) was used as a control. Moreover, the broth was inoculated for $3 \mathrm{~h}$ and the optical density (OD) was measured at $600 \mathrm{~nm}$. The acid resistance was determined by the following equation: Survival Rate (\%): [OD (After treatment)/OD (Before treatment)] $\times 100 \%$. Strains with viability more than $80 \%$ were selected for further analysis.

The ability of isolates to grow in presence of bile salt was measured. This was accomplished with $0.3 \% \mathrm{w} / \mathrm{v}$ oxgall and Control was maintained employing MRS broth. The samples were inoculated at $37^{\circ} \mathrm{C}$ for $4 \mathrm{~h}$ and $\mathrm{OD}_{620}$ of samples was measured to check the viability of cells. The oxgall resistance was determined by the following equation: Survival Rate (\%): [OD (After treatment)/OD (Before treatment)] $\times 100 \%$.

\subsection{Antimicrobial activity}

The antimicrobial features of isolates were performed by agar well diffusion assay. In this method, plates containing Mueller-Hinton agar medium impregnated with different indicator bacteria was used (Table 1). A sterile pasteurized pipette was used to create wells in medium. Finally, $100 \mu \mathrm{L}$ of supernatants of isolates were placed inside each wells and plates were then incubated at $37^{\circ} \mathrm{C}$ for $24 \mathrm{~h}$. After incubation time, the measured inhibition halo zone diameters were statistically analyzed.

\subsection{Antibiotic susceptibility}

The disc diffusion method was performed for evaluation of the susceptibility of isolates to some high-consumption and clinically important antibiotics listed in Table 2. For this purpose, isolates were streaked over the solidified MRS medium and antibiotic disks were placed on the medium and incubated overnight 
at $37^{\circ} \mathrm{C}$. Finally, the diameters of inhibition zone around disks were measured by digital caliper.

\subsection{Cell surface hydrophobicity}

The adhesion ability of isolates to xylene and toluene was determined as previously described by ${ }^{9}$. The test was performed in triplicate and expressed as:

Hydrophobicity $(\%)=(1-\mathrm{A} 1 / \mathrm{A} 0) \times 100$.

Where $A_{0}$ represents the initial absorbance at $600 \mathrm{~nm}$ before adding xylene and toluene; $A_{1}$ represents absorbance after $4 \mathrm{~h}$ inoculated with xylene and toluene.

\subsection{Autoaggregation assay}

The ability of isolates to auto-aggregate was performed according to the method described by ${ }^{10}$. Auto-aggregation percentage was determined using the following equation:

Auto-aggregation $(\%)=1-(\mathrm{At} / \mathrm{A} 0) \times 100$

Where $\mathrm{A}_{0}$ represents absorbance at $\mathrm{t}=0$ and at represents absorbance at time $\mathrm{t}$.

\subsection{Coaggregation assay}

Co-aggregation of isolates against Staphylococcus aureus and bacillus cereus was performed based on method used by ${ }^{11}$. Co-aggregation percentage was calculated based on equation: $\%=A_{0}-A_{t} / A_{t} \times 100$

\subsection{Adhesion ability to human intestinal cells}

Selected isolates were explored for their attachment capacity to the human colon carcinoma cell line Caco-2. RPMI medium supplemented with $10 \%$ heatinactivated fetal bovine serum and $1 \%$ penicillin-streptomycin blend were utilized and cells were refined on 24 -well tissue culture plates and incubated at $37{ }^{\circ} \mathrm{C}$ in $5 \% \mathrm{CO}_{2}$ under a relatively humidified atmosphere until a confluent monolayer was formed. Sometime recently the attachment measure, the media within the wells containing a Caco-2 cell monolayer were evacuated and supplanted with new antibiotic-free RPMI. From that point, $1 \times 10^{7} \mathrm{CFU} / \mathrm{mL}^{\circ}$ of isolates was included to each well with a add up to volume of $1 \mathrm{~mL}$ and after that incubated for $3 \mathrm{~h}$ at $37^{\circ} \mathrm{C}$ under an atmosphere of $5 \%(\mathrm{v} / \mathrm{v}) \mathrm{CO}_{2}$. The wells were washed twice with a sterile pre-warmed PBS solution to evacuate non-attached bacterial cells. One $\mathrm{mL}$ of $1 \%(\mathrm{v} / \mathrm{v})$ Triton X-100 was included to each well to withdraw the cells from the wells and the blend was mixed for $10 \mathrm{~min}$. To measure the viable cell count, the cell suspension was plated onto MRS agar and hatched at $37^{\circ} \mathrm{C}^{12}$.

\subsection{Cholesterol assimilation}

Cholesterol removal capability of the isolates was determined using o-phthaldehyde procedure described previously by ${ }^{13}$. The isolates were inoculated into MRS broth supplemented with water-soluble cholesterol (polyoxyethanylcholesterylsebacate; Sigma) with a concentration of $150 \mu \mathrm{g} / \mathrm{mL}$ and $0.3 \%$ bile oxgall, followed by overnight incubation at $37^{\circ} \mathrm{C}$. After the incubation period, the cell pellet was obtained by centrifugation at $4250 \times \mathrm{g}$ for $15 \mathrm{~min}$, and the remaining cholesterol in the upper layer was measured by the o-paraldehyde method.

\subsection{Biofilm formation}

The ability of isolates to form biofilm was determined according to method described by ${ }^{14}$ with some modifications. For this purpose, the wells of a sterile 6 well tissue culture plate were filled with $5 \mathrm{~mL}$ of MRS broth supplemented with $500 \mu \mathrm{L}$ of overnight isolates $\left(10^{7}-10^{8} \mathrm{CFU} / \mathrm{mL}\right)$. Cultures were incubated anaerobically for $48 \mathrm{~h}$ at $37{ }^{\circ} \mathrm{C}$. After this period, the wells were gently washed three times with $5 \mathrm{~mL}$ of sterile distilled water. Then, $3 \mathrm{~mL}$ of methanol was used for $15 \mathrm{~min}$ to fix the attached bacteria and then plates were emptied and dried at room temperature. Afterwards, $3 \mathrm{~mL}$ of a $2 \%$ ( $\mathrm{v} / \mathrm{v}$ ) crystal violet solution was poured in the wells and held at room temperature for $5 \mathrm{~min}$. Finally, to release stain from Adherent cells, $2 \mathrm{~mL}$ of $33 \%$ ( $\mathrm{v} / \mathrm{v}$ ) glacial acetic acid was used and the optical density (OD) of each well was measured at $595 \mathrm{~nm}$ using a platereader (Microplatereader, Bio-Rad, Hercules; CA, USA).

\subsection{Exopolysaccharide (EPS) production}

To assess EPS production ability of isolates, method described by ${ }^{15}$ with slight modification was used. Briefly, modified MRS agar medium (replacing glucose with $100 \mathrm{~g} / \mathrm{L}$ of sucrose) was used and isolates were streaked on cultures and incubated at $37^{\circ} \mathrm{C}$ for $24 \mathrm{~h}$. Metal loop was used to drag up formed colonies. If the length of slime was above $1.5 \mathrm{~mm}$, the isolate was considered positive slimy producers.

\subsection{Molecular identification}

\subsubsection{Genomic DNA extraction}

The total genomic DNA of the isolates was extracted through the procedure designed in our laboratory. For this purpose, a single colony of each isolate was placed in 0.2 tube and $20 \mu \mathrm{L}$ lysis buffer $(0$ was poured inside the tube. The tubes were gently vortexed until the contents were completely homogeneous and were placed for one hour at room temperature. Then, they were incubated in thermal cycler PTC 200 ( MJC research, Waltham, USA) for 10 min at $85{ }^{\circ} \mathrm{C}$. After this period, $150 \mu \mathrm{L}$ deionized water was added to tubes and they were centrifuged at $8000 \times \mathrm{g}$ for 5 min. Finally, the upper phase containing genomic DNA was removed and poured in new tubes. The genomic DNA was stored at refrigerator until using. 


\subsubsection{Amplification of 16S-rRNA gene by polymerase chain reaction (PCR)}

The amplification of genomic DNA samples of the isolates was performed in a thermal cycler PTC 200 by using LAB-specific universal primers ${ }^{16}$. The following temperature profile was used to amplify DNA: an initial denaturation at $95^{\circ} \mathrm{C}$ for 5 min, followed by 32 cycles of denaturation at $94{ }^{\circ} \mathrm{C}$ for 60 sec, annealing at $59^{\circ} \mathrm{C}$ for $60 \mathrm{sec}$, extension at $72{ }^{\circ} \mathrm{C}$ for $60 \mathrm{sec}$, and a final extension step at $72{ }^{\circ} \mathrm{C}$ for 5 min. Electrophoresis in a $0.8 \%$ (w/v) agarose gel was used to resolve the PCR products and visualized via ethidium bromide staining.

\subsubsection{S-rRNA gene sequencing}

The PCR products of the 16S-rRNA gene (1544 bp) were amplified using the mentioned primer set. The PCR products were sequenced at Sinaclone Corporation, Tehran, Iran. The sequences were then analyzed using the BLAST program of the National Center for Biotechnology Information (http://www.ncbi.nlm.nih.gov/BLAST).

\subsection{Statistical analysis}

To determine the significant differences between the parameters of each isolates $(P \leq 0.05)$, analysis of variance (ANOVA) and Duncan's test were used. Moreover, excel 2013 (Microsoft Corporation) and SPSS (IBM SPSS Statistics 20) were used for formal statistical analysis.

\subsection{Unsupervised clustering algorithms}

The heat-map was generated using Euclidean distance measure and Ward clustering methods implemented in ggplot2 package of R software as prescribe in

17. For unsupervised clustering of samples based on desired probiotic characteristics, principal component analysis (PCA) method was used. This algorithm provides a means to achieve unbiased dimensionality reduced structure of studies strains ${ }^{18}$.

\section{Results}

\subsection{Morphological and biochemical assays}

A total of 31 rod- and cocci-shaped colonies were grown and isolated on culture media. Each colony was separately propagated for assessments. Based on Gram-positive and catalase-negative assays, 19 isolates were identified as LAB isolates and selected for further analysis.

\subsection{Acid and bile tolerance}

Figure 1 represents the survival rates of 19 rod- and cocci-shaped isolates after $3 \mathrm{~h}$ of incubation at pH 3.0. Based on the findings, all 19 isolates retained their viability and percent survival rates of evaluated isolates ranged from $26-100 \%$ after $3 \mathrm{~h}$ of incubation at $37^{\circ} \mathrm{C}$ (data not shown). The isolates with the most efficient resistance to low pH conditions were isolates $\mathrm{F} 3, \mathrm{~F} 12$, and $\mathrm{F} 7$, with survival rates of $99 \%, 96 \%$, and $94 \%$, respectively. Conversely, isolates $\mathrm{F} 4$, $\mathrm{F} 9$, and F11 indicated the lowest viability after $3 \mathrm{~h}$, with survival rates of $26 \%, 29 \%$, and $32 \%$, respectively.

The survival rates of 19 isolates in $0.3 \%$ oxgall are indicated in Fig. 1 . All 19 isolates appeared resistant to high bile salt condition, despite variations in the degree of viability. Percent survival rates of evaluated isolates ranged from $31-100 \%$ after $4 \mathrm{~h}$ of incubation at $37^{\circ} \mathrm{C}$. The highest tolerance was observed for isolate F7, followed by isolates F3, and F15, with survival rates of $100 \%, 95 \%$, and $93 \%$, respectively. Isolates F11, F17, and F9 showed the lowest viability after $4 \mathrm{~h}$ of incubation in media containing $0.3 \%$ oxgall, with survival rates of $31 \%, 33 \%$, and $36 \%$, respectively.

\subsection{Antimicrobial activity}

Table 1 indicates the antibacterial activity of the evaluated isolates against several Gram-positive and Gram-negative bacteria. Eight important aquatic pathogens including Vibrio harveyi (PTCC 1755), Vibrio cholera (PTCC 1611), Streptococcus iniae (PTCC 1887), Vibrio alginolyticus (ATCC 17749), Vibrio fluvialis (ATCC 33809), Vibrio parahaemolyticus (ATCC 17802), Streptococcus agalactia (ATCC 12386), and Clostridium cochlearium (PTCC 1263) were used. The neutralized supernatant fluids of isolates F15 and F12 were able to inhibit the growth of all the eight indicator bacteria. Meanwhile isolates F11, F14, and F18 were able to inhibit the growth of two Gram-positive indicators named St. iniae and St. agalactia, while the neutralized supernatant fluids of these isolates were ineffective against any of the Gram-negative pathogen tested in the work.

\subsection{Antibiotic susceptibility}

The selected isolates were assessed for their antibiotic susceptibility against ciprofloxacin $(5 \mu \mathrm{g})$, ampicillin (10 $\mu \mathrm{g})$, vancomycin $(30 \mu \mathrm{g})$, erythromycin (15 $\mu \mathrm{g})$, azithromycin $(15 \mu \mathrm{g})$, gentamicin $(10 \mu \mathrm{g})$, penicillin $(10 \mu \mathrm{g})$, chloramphenicol $(30 \mu \mathrm{g})$, tetracycline $(30 \mu \mathrm{g})$, and streptomycin $(10 \mu \mathrm{g})$. Based on the results illustrated in Table 2, isolate F12 was susceptible to all the tested antibiotics, while isolate F18 was resistant to all the tested antibiotics. The most widespread resistance among the isolates was observed against gentamycin, penicillin, and ciprofloxacin which were detected in $57.9 \%$ of the isolates, while the least resistance was observed against tetracycline which was detected only in isolate F18.

\subsection{Cell surface hydrophobicity}

The cell surface hydrophobicity percentages of the isolates ranged from $3.7 \pm 1.6 \%$ to $70.2 \pm 2.0 \%$ and $2.2 \pm 1.6 \%$ to $76.4 \pm 2.1 \%$ with toluene and xylene, respectively (Table 3). The highest hydrophobicity percentages with toluene and xylene were observed for isolates F15 (70.2 $\pm 2.0 \%)$ and F12 (76.4 $\pm 2.1 \%)$, respectively. Conversely, isolates F18 (3.7 $\pm 1.6 \%)$ and F11 $(2.2 \pm 1.6 \%)$ possessed the least hydrophobicity with toluene and xylene, respectively. These results display that hydrophobicity is a strain-dependent property and that LAB strains are naturally hydrophilic.

\subsection{Autoaggregation assay}


Results of the autoaggregation of the 19 selected isolates are illustrated in Table 3 . Values of autoaggregation ranged from $1.3 \pm 0.5 \%$ to $82.6 \pm 1.4 \%$ after $4 \mathrm{~h}$ of incubation. The highest autoaggregation values was observed for isolate F7, with value of $82.6 \pm 1.4 \%$, while the least value was obtained for isolate 11 , with $1.3 \pm 0.5 \%$ autoaggregation after $4 \mathrm{~h}$ of incubation.

\subsection{Coaggregation assay}

Table 3 shows the results of the coaggregation ability of the 19 evaluated isolates. The coaggregation percentages ranged from $2.5 \pm 1.2 \%$ to $58.3 \pm 1.8 \%$ with Staphylococcus aureus and from $1.4 \pm 0.9 \%$ to $61.2 \pm 2.2 \%$ with Bacillus cereus. The highest coaggregation value with $S$. aureus was observed for isolate F12 $(58.3 \pm 1.8 \%)$, while the highest value for coaggregation with $B$. cereus was obtained for isolate F3 $(61.2 \pm 2.2 \%)$. The least coaggregation values with $S$. aureus and $B$. cereus were obtained for isolates F18 $(2.5 \pm 1.2)$ and F19 $(1.4 \pm 0.9)$.

\subsection{Adhesion assay}

Based on the findings illustrated in Table 3, only five isolates (F3, F7, F8, F12, and F15) were able to adhere to Caco-2 cells. The adhesion values ranged from 0 to $38.7 \pm 1.5 \%$. Isolate F12 showed the highest ability to adhere to epithelial cells, followed by isolates F8 ( $31.4 \pm 2.1 \%), F 7(27.5 \pm 1.9 \%), F 3(24.7 \pm 1.7 \%)$, and F15 (23.2 \pm 1.55$)$.

\subsection{Cholesterol removal}

Table 3 illustrates the cholesterol assimilation patterns of the selected isolates. Cholesterol assimilation values varied among the 19 evaluated isolates and ranged from $3.6-78.2 \%$. Isolate F12 showed the highest removal cholesterol ability, with value of $78.2 \%$, followed by isolates F3 and F7, with values of $64.5 \%$ and $59.7 \%$, respectively. Isolates F18 showed the lowest cholesterol assimilation (3.6\%), followed by isolates F19 and F11, with values of $7.25 \%$ and $11.8 \%$.

\subsection{Biofilm formation}

The ability of isolates to form biofilm in MRS medium was illustrated in Fig. 2. Results showed that 17 out of 19 isolates were able to form biofilm. The highest biofilm formation values were observed for isolate $F 15$, with $\mathrm{OD}_{600}=1.81$, followed by isolates $F 3\left(\mathrm{OD}_{600}=1.65\right), \mathrm{F7}\left(\mathrm{OD}_{600}=1.55\right)$, and $\mathrm{F} 12\left(\mathrm{OD} \mathrm{D}_{600}=\right.$ 1.42). Four out of 17 isolates were strong biofilm producers, 6 isolates were moderate biofilm producers and 7 isolates were weak biofilm producers.

\subsection{Exopolysaccharide (EPS) production}

The results showed that only six isolates (F3, F5, F7, F9, F12, and F15) were able to produce EPS. The highest values of EPS production were observed for isolate F3, followed by F15, F7, and F12.

\subsection{Molecular identification}

The 16S-rRNA gene sequencing was used to validate the phenotypic characterization of the selected LAB isolates. The PCR-amplified 1544 bp fragments of the 16S-rRNA gene of the isolates were sequenced and blasted with the sequences deposited in GeneBank. Amplification of the 16S-rRNA genes of 19 LAB isolates confirmed that all isolates belonged to the 4 genera of LAB including Lactobacillus, Lactococcus, Pediococcus, and Enterococcus. Lactobacillus isolates classified to 3 species including $L$ b. plantarum (F1, F6, F12), Lb. acidophilus (F3, F5), and Lb. fermentum (F16). Pediococcus isolates classified to 3 species including $P$. Iolli (F2, F4), P. pentosaceus (F7, F13, F14), and $P$. acidilactici (F9, F15). Meanwhile, Enterococcus isolates classified to 2 species, E. hirae (F11, F18) and E. lactis (F19), while all Lactococcus isolates belonged to Lc. Lactis species (F8, F10, F17).

\subsection{Clustering analysis using Heat map and PCA methods}

Identified and characterized strains with desired probiotic features such as acid and bile tolerance, cell surface hydrophobicity, auto-aggregation and coaggregation were subjected to cluster analysis based on unsupervised methods. Unsupervised methods are types of learning algorithm used to knowledge discovery from datasets that are neither classified nor labeled ${ }^{19-21}$. As depicted in Fig. 3, Identified strains clustered in three distinct groups by Ward and PCA methods. It is obvious cluster I in heat map included the isolates F3, F7, F12, and F15, whereas; remaining nine strains created the other two clades. The projection of identified strains diversity based on the PC1 and PC2 highlighted the diversity of identified bacteria. In total, about $97 \%$ of the variation in the characterized bacteria was explained by two principal components (Table 3). More interestingly, congruence was displayed between the results of two applied methods in clustering the identified bacteria based on probiotic characteristics.

\section{Discussion}

There are several criteria for bacteria to recognize as probiotic. One of the most important features is tolerance to low $\mathrm{pH}$ and high bile salt concentrations. They must overcome physical and chemical barriers in the gastrointestinal tract to be able to transit through the stomach. Probiotics to be able to survive and grow and could exert their action in the small intestine must be tolerant to high bile salt conditions ${ }^{22}$. In this work, the evaluated isolates indicated varying values of viability in $\mathrm{pH} 3$ and $0.3 \%$ bile oxgall. The isolates $\mathrm{F} 3, \mathrm{~F} 12, \mathrm{~F} 15$, and $\mathrm{F} 7$ showed more than $90 \%$ viability at $\mathrm{pH} 3$ and $0.3 \%$ bile oxgall. High survival rates of $L A B$ especially $L$ b. plantarum ${ }^{9,23}$, and $P$. pentosaceus and $P$. acidilactici ${ }^{24-26}$ at gastric $\mathrm{pH}$ of 3.0 and $0.3 \%$ bile concentration have been reported.

The antimicrobial properties of probiotics are attributed to their metabolite productions including organic acids, hydrogen peroxide, and bacteriocin ${ }^{27}$. In this study, isolates were investigated against two Gran-positive (St. iniae and St. agalactia) and six Gram-negative (V. harveyi, V. cholera, V. alginolyticus, V. parahaemolyticus, and Cl. cochlearium) indicators. Evaluated isolates showed better antibacterial effects on Gram-positive than Gram-negative indicators, which this could be due to the outer membrane of Gram-negative bacteria. All the 19 isolates inhibited the growth of St. iniae and St. agalactia. Isolates F12 and F15 showed the best results and were able to inhibit the growth of all the 8 evaluated indicators. 
Another strange property of probiotics is their ability to form biofilms. It can promote colonization within the inner wall of the intestine and longer lasting quality of $L A B$, thus maintaining a strategic distance from colonization by pathogenic microorganisms ${ }^{28}$. The ability of form biofilm is of great economic importance to food-processing companies, as subsequent microorganisms attached to industrial devices can form highly resistant biofilms, and their strong tendency to adhere to the surface facilitates the separation of biomass during the fermentation process ${ }^{29}$. Isolates F3, F7, F12, and F15 showed the strong biofilm formation ability; cause them to be suitable for use as biocontrol agents.

There are many studies which investigated the cholesterol reduction ability of $L A B$ isolates ${ }^{13,30,31}$. The reduction of serum cholesterol values is important to prevent the coronary heart disease due to the main risk factor for the progression of coronary heart disease is hypercholesterolemia ${ }^{32}$. Isolates F12, F3, and F7 showed remarkable cholesterol removal ability, with values of more than $59 \%$.

For selection of functional LAB isolates, two groups of antibiotics are recommended; first those are inhibitors of cell wall synthesis such as vancomycin and ampicillin, and second those are inhibitors of protein synthesis including erythromycin, chloramphenicol, clindamycin, gentamycin, kanamycin, tetracycline, and streptomycin ${ }^{33}$. In this study, the LAB isolates indicated susceptibility to chloramphenicol (89.47\%), tetracycline (94.73\%), erythromycin (84.21\%), ampicillin (84.21\%), azithromycin (52.63\%), gentamycin (42.11\%), streptomycin (57.89\%), penicillin (42.11\%), vancomycin (52.63\%), and ciprofloxacin (42.11\%). The results of this study is consistent with the previous results which showed that LAB are susceptible to antibiotics inhibiting the proteins synthesis, such as chloramphenicol, tetracycline, and erythromycin, and are resistance towards glycopepticides antibiotics such as vancomycin ${ }^{34}$, and aminoglycosides antibiotics including streptomycin, kanamycin, and gentamycin ${ }^{35}$. Several LAB species belonged to especially Lactobacillus, Pediococcus and Leuconostoc have been reported to exhibit high levels of natural resistance to vancomycin, which is useful to separate them from other Gram-positive bacteria $^{25}$.

A desirable property of probiotic bacteria is colonization in intestinal wall ${ }^{13}$. Hydrophobicity, auto-aggregation and adhesion to epithelial cells could help probiotics to colonize in intestinal cells. The hydrophobicity of the bacterial cell surface is one of the most important factors for probiotics to be colonized in human and animal gastrointestinal tracts. In this study, the cell surface hydrophobicity percentages of the isolates ranged from $3.7 \pm 1.6 \%$ to $70.2 \pm 2.0 \%$ with toluene and $2.2 \pm 1.6 \%$ to $76.4 \pm 2.1 \%$ with xylene. This result confirms the results of several previous researches reported by ${ }^{36-38}$. Four out of 19 isolates showed both considerable cell surface hydrophobicity and high auto-aggregation (> 67\%), which indicated good colonization potential ${ }^{39}$. According to Vallejo et al. (2008), strains with values of autoaggregation higher than $65 \%$ are strongly autoaggregating. Isolates F3, F7, F12, and F15 showed remarkable autoaggregation ability; making these isolates interesting candidates for potential probiotic applications. The capacity to attach to epithelial cells and mucosal surfaces may be a critical feature of bacterial isolates to be utilized as probiotics. Results showed that only isolates F3, F7, F8, F12, and F15 were able to adhere to Caco-2 cells. The adhesion ability of these 4 isolates to Caco-2 cell had also significant coherence to auto-aggregation and hydrophobicity. The adhesion rates of these isolates to Caco- 2 cells were between $23 \%$ and $38 \%$. It seems that adhesion ability is correlated with auto-aggregation ${ }^{30}$. These results also support the correlation between adhesion and auto-aggregation.

In conclusion, several isolates evaluated in this study showed potential probiotic properties. The majority of evaluated isolates showed high antimicrobial activities against potentially pathogenic Gram-positive and Gram-negative indicator bacteria which deserve them to be used as biocontrol agents in fishery. Regarding the interesting probiotic properties, the highest values of autoaggregation and hydrophobicity as well as a high value of coaggregation and a high capacity for biofilm formation, isolates F3, F7, F12, and F15 could be candidates to be used as bio-control agents in fishery to protect against pathogenic microorganisms and improve health care and food safety by avoiding the use of additives. Cluster characterization of identified potential probiotic bacteria based on two above mentioned methods also highlighted the priority of isolates F3, F7, F12, and F15 as bio-control agents in fishery industry. In line with our study, prior finding also highlighted the effectiveness of above-mentioned methods for characterization and prioritization of newly identified isolates ${ }^{17,40}$. Also our empirical and cluster analysis based on unsupervised methods prioritized some isolates as biocontrol agent candidates in fishery industry, however; further analysis would be needed.

\section{Declarations}

\section{Ethics statement}

No ethical issues were promulgated.

\section{Conflicts of interest}

The authors declare no conflict of interests.

\section{Author contributions}

YN: designing experiment. AM: writing \& doing tests. BP: revising.

\section{Funding}

This work was supported by the Agricultural Biotechnology Research Institute of Iran [grant numbers 3-05-0551-88020].

\section{Acknowledgements}

The financial support of the Agricultural Biotechnology Research Institute of Iran (ABRII) is gratefully acknowledged. 


\section{References}

1. Subasinghe, R. World aquaculture 2015: a brief overview.FAO Fisheries and Aquaculture Report(2017)

2. Mukherjee, A. \& Ghosh, K. Antagonism against fish pathogens by cellular components and verification of probiotic properties in autochthonous bacteria isolated from the gut of an I ndian major carp, C atla catla (H amilton). Aquac. Res, 47, 2243-2255 (2016).

3. Giri, S. S. et al. Antagonistic activity of cellular components of potential probiotic bacteria, isolated from the gut of Labeo rohita, against Aeromonas hydrophila. Probiotics and Antimicrobial Proteins, 3, 214-222 (2011).

4. Han, B. et al. Effects of dietary Bacillus licheniformis on growth performance, immunological parameters, intestinal morphology and resistance of juvenile Nile tilapia (Oreochromis niloticus) to challenge infections. Fish \& shellfish immunology, 46, 225-231 (2015).

5. Lazado, C. C., Caipang, C. M. A. \& Estante, E. G. Prospects of host-associated microorganisms in fish and penaeids as probiotics with immunomodulatory functions. Fish \& shellfish immunology, 45, 2-12 (2015).

6. Mohammadian, T., Alishahi, M., Tabandeh, M., Ghorbanpoor, M. \& Gharibi, D. Effect of Lactobacillus plantarum and Lactobacillus delbrueckii subsp. bulgaricus on growth performance, gut microbial flora and digestive enzymes activities in Tor grypus (Karaman, 1971). Iranian Journal of Fisheries Sciences, 16, 296-317 (2017).

7. Ghanbari, M., Kneifel, W. \& Domig, K. J. A new view of the fish gut microbiome: advances from next-generation sequencing., 448, 464-475 (2015).

8. Clements, K. D., Angert, E. R., Montgomery, W. L. \& Choat, J. H. (Wiley Online Library, 2014)

9. Rodríguez-Sánchez, S., Fernández-Pacheco, P., Seseña, S., Pintado, C. \& Palop, M. L. Selection of probiotic Lactobacillus strains with antimicrobial activity to be used as biocontrol agents in food industry. $L W T, 143,111142$ (2021).

10. Angmo, K., Kumari, A. \& Bhalla, T. C. Probiotic characterization of lactic acid bacteria isolated from fermented foods and beverage of Ladakh. LWT-food Science and Technology, 66, 428-435 (2016)

11. Zuo, F. et al. Characterization and in vitro properties of potential probiotic Bifidobacterium strains isolated from breast-fed infant feces. Annals of Microbiology, 66, 1027-1037 (2016).

12. Kiani, A. et al. Tarkhineh as a new microencapsulation matrix improves the quality and sensory characteristics of probiotic Lactococcus lactis KUMS-T18 enriched potato chips. Sci. Rep, 11, 1-13 (2021).

13. Nami, Y., Bakhshayesh, R. V., Manafi, M. \& Hejazi, M. A. Hypocholesterolaemic activity of a novel autochthonous potential probiotic Lactobacillus plantarum YS5 isolated from yogurt. LWT, 111, 876-882 (2019).

14. Gómez, N. C., Ramiro, J. M., Quecan, B. X. \& de Franco, M. Use of potential probiotic lactic acid bacteria (LAB) biofilms for the control of Listeria monocytogenes, Salmonella Typhimurium, and Escherichia coli 0157: H7 biofilms formation. Frontiers in microbiology, 7, 863 (2016).

15. Fguiri, I. et al. Isolation and characterisation of lactic acid bacteria strains from raw camel milk for potential use in the production of fermented Tunisian dairy products. International Journal of Dairy Technology, 69, 103-113 (2016).

16. Nami, Y., Haghshenas, B. \& Khosroushahi, A. Y. Molecular identification and probiotic potential characterization of lactic acid bacteria isolated from human vaginal microbiota. Advanced pharmaceutical bulletin, 8, 683 (2018).

17. Nami, Y., Panahi, B., Jalaly, H. M., Bakhshayesh, R. V. \& Hejazi, M. A. Application of unsupervised clustering algorithm and heat-map analysis for selection of lactic acid bacteria isolated from dairy samples based on desired probiotic properties. LWT, 118, 108839 (2020).

18. Panahi, B., Tajaddod, S., Jallali, M., Hejazi, H. \& Zeinalabedini, M. M. A. \& Variability and association among some pomological and physiochemical traits in spring frost tolerant genotypes of Persian walnut (Juglans regia L.) and selection of genotypes with superior traits based on machine learning algorithms. Genetic Resources and Crop Evolution,1-13(2021)

19. Panahi, B., Mohammadi, S. A. \& Doulati-Baneh, H. Characterization of Iranian grapevine cultivars using machine learning models. Proceedings of the National Academy of Sciences, India Section B: Biological Sciences, 1-7 (2019)

20. Panahi, B., Mohammadi, S. A. \& Doulati-Baneh, H. Characterization of Iranian grapevine cultivars using machine learning models. Proceedings of the National Academy of Sciences, India Section B: Biological Sciences 90, 615-621 (2020)

21. Nami, Y., Imeni, N. \& Panahi, B. Application of machine learning in bacteriophage research. BMC microbiology, 21, 1-8 (2021).

22. Mojgani, N., Torshizi, M. A. \& Rahimi, S. Screening of locally isolated lactic acid bacteria for use as probiotics in poultry in Iran. The Journal of Poultry Science, 44, 357-365 (2007).

23. Missaoui, J., Saidane, D., Mzoughi, R. \& Minervini, F. Fermented seeds ("Zgougou”) from aleppo pine as a novel source of potentially probiotic lactic acid bacteria. Microorganisms, 7, 709 (2019).

24. Shukla, R. \& Goyal, A. Probiotic potential of Pediococcus pentosaceus CRAG3: a new isolate from fermented cucumber. Probiotics and antimicrobial proteins, 6, 11-21 (2014).

25. Gupta, S., Mohanty, U. \& Majumdar, R. K. Isolation and characterization of lactic acid bacteria from traditional fermented fish product Shidal of India with reference to their probiotic potential. $L W T, 146,111641$ (2021).

26. Erkkilä, S. \& Petäjä, E. Screening of commercial meat starter cultures at low pH and in the presence of bile salts for potential probiotic use. Meat science, 55, 297-300 (2000).

27. İspirli, H., Demirbaş, F. \& Dertli, E. Characterization of functional properties of Enterococcus faecium strains isolated from human gut. Canadian journal of microbiology, 61, 861-870 (2015).

28. Terraf, M. L., Juárez Tomás, M., Nader-Macías, M. \& Silva, C. Screening of biofilm formation by beneficial vaginal lactobacilli and influence of culture media components. Journal of applied microbiology, 113, 1517-1529 (2012).

Page $7 / 11$ 
29. Speranza, B. et al. Biofilm formation by potentially probiotic Saccharomyces cerevisiae strains. Food microbiology, 87, 103393 (2020).

30. Kouhi, F., Mirzaei, H., Nami, Y., Khandaghi, J. \& Javadi, A. Potential probiotic and safety characterisation of Enterococcus bacteria isolated from indigenous fermented Motal cheese.International Dairy Journal,105247(2021)

31. Damodharan, K., Lee, Y. S., Palaniyandi, S. A., Yang, S. H. \& Suh, J. W. Preliminary probiotic and technological characterization of Pediococcus pentosaceus strain KID7 and in vivo assessment of its cholesterol-lowering activity. Frontiers in microbiology, 6, 768 (2015).

32. Shehata, M., Sohaimy, E., El-Sahn, S., Youssef, M. \& M. A. \& Screening of isolated potential probiotic lactic acid bacteria for cholesterol lowering property and bile salt hydrolase activity. Annals of Agricultural Sciences, 61, 65-75 (2016).

33. Additives, E. P. \& Feed, P. o. S. u. i. A. Guidance on the assessment of bacterial susceptibility to antimicrobials of human and veterinary importance. EFSA Journal, 10, 2740 (2012).

34. Katla, A. K., Kruse, H., Johnsen, G. \& Herikstad, H. Antimicrobial susceptibility of starter culture bacteria used in Norwegian dairy products. International journal of food microbiology, 67, 147-152 (2001).

35. Zhou, J., Pillidge, C., Gopal, P. \& Gill, H. Antibiotic susceptibility profiles of new probiotic Lactobacillus and Bifidobacterium strains. International journal of food microbiology, 98, 211-217 (2005).

36. Nami, Y. et al. Novel autochthonous lactobacilli with probiotic aptitudes as a main starter culture for probiotic fermented milk. LWT, 98, 85-93 (2018).

37. Dowarah, R., Verma, A. K., Agarwal, N., Singh, P. \& Singh, B. R. Selection and characterization of probiotic lactic acid bacteria and its impact on growth, nutrient digestibility, health and antioxidant status in weaned piglets. PloS one, 13, e0192978 (2018).

38. Kiani, A. et al. Application of Tarkhineh fermented product to produce potato chips with strong probiotic properties, high shelf-life, and desirable sensory characteristics. Frontiers in microbiology12 (2021)

39. Reuben, R., Roy, P., Sarkar, S., Alam, A. R. U. \& Jahid, I. Characterization and evaluation of lactic acid bacteria from indigenous raw milk for potential probiotic properties. Journal of dairy science, 103, 1223-1237 (2020).

40. Mallappa, R. H. et al. Screening and selection of probiotic Lactobacillus strains of Indian gut origin based on assessment of desired probiotic attributes combined with principal component and heatmap analysis. LWT, 105, 272-281 (2019).

\section{Tables}

Table 1 Zone inhibition $(\mathrm{mm})$ of antimicrobial properties of isolates

\begin{tabular}{|c|c|c|c|c|c|c|c|c|}
\hline \multirow[t]{2}{*}{ Isolates } & \multicolumn{8}{|c|}{ Indicator bacteria } \\
\hline & $\begin{array}{l}\text { Vibrio } \\
\text { harveyi }\end{array}$ & $\begin{array}{l}\text { Vibrio } \\
\text { cholera }\end{array}$ & $\begin{array}{l}\text { Streptococcus } \\
\text { iniae }\end{array}$ & $\begin{array}{l}\text { Vibrio } \\
\text { alginolyticus }\end{array}$ & $\begin{array}{l}\text { Vibrio } \\
\text { fluvialis }\end{array}$ & $\begin{array}{l}\text { Vibrio } \\
\text { parahaemolyticus }\end{array}$ & $\begin{array}{l}\text { Streptococcus } \\
\text { agalactia }\end{array}$ & $\begin{array}{l}\text { Clostridium } \\
\text { cochlearium }\end{array}$ \\
\hline $\mathrm{F} 1$ & 0 & 17 & 14 & 17 & 19 & 0 & 21 & 22 \\
\hline $\mathrm{F} 2$ & 8 & 0 & 21 & 20 & 0 & 17 & 19 & 13 \\
\hline F3 & 14 & 18 & 10 & 0 & 16 & 13 & 22 & 20 \\
\hline F4 & 0 & 15 & 17 & 9 & 21 & 16 & 16 & 19 \\
\hline F5 & 16 & 0 & 11 & 12 & 9 & 18 & 13 & 14 \\
\hline F6 & 11 & 13 & 20 & 8 & 0 & 21 & 17 & 14 \\
\hline F7 & 22 & 21 & 19 & 0 & 12 & 0 & 10 & 18 \\
\hline F8 & 13 & 11 & 11 & 11 & 17 & 12 & 18 & 0 \\
\hline F9 & 0 & 0 & 16 & 15 & 19 & 9 & 22 & 14 \\
\hline F10 & 9 & 10 & 14 & 0 & 0 & 8 & 15 & 21 \\
\hline F11 & 0 & 0 & 22 & 0 & 0 & 0 & 24 & 0 \\
\hline F12 & 19 & 22 & 28 & 23 & 19 & 21 & 31 & 26 \\
\hline F13 & 8 & 9 & 12 & 0 & 12 & 15 & 16 & 0 \\
\hline F14 & 0 & 0 & 20 & 0 & 0 & 0 & 19 & 0 \\
\hline F15 & 21 & 19 & 26 & 22 & 17 & 14 & 29 & 25 \\
\hline F16 & 0 & 7 & 16 & 19 & 8 & 19 & 19 & 18 \\
\hline F17 & 14 & 11 & 19 & 10 & 0 & 16 & 21 & 12 \\
\hline F18 & 0 & 0 & 24 & 0 & 0 & 0 & 17 & 0 \\
\hline F19 & 12 & 8 & 21 & 17 & 18 & 0 & 12 & 0 \\
\hline
\end{tabular}


Table 2 Antibiotic susceptibility profile of isolates

\begin{tabular}{|c|c|c|c|c|c|c|c|c|c|c|}
\hline \multirow[t]{2}{*}{ Isolates } & \multicolumn{10}{|l|}{ Antibiotics } \\
\hline & $\begin{array}{l}\text { ampicillin } \\
(10 \mu \mathrm{g})\end{array}$ & $\begin{array}{l}\text { vancomycin } \\
(30 \mu \mathrm{g})\end{array}$ & $\begin{array}{l}\text { erythromycin } \\
(15 \mu \mathrm{g})\end{array}$ & $\begin{array}{l}\text { azithromycin } \\
(15 \mu \mathrm{g})\end{array}$ & $\begin{array}{l}\text { gentamycin } \\
(10 \mu \mathrm{g})\end{array}$ & $\begin{array}{l}\text { penicillin } \\
(10 \mu \mathrm{g})\end{array}$ & $\begin{array}{l}\text { chloramphenicol } \\
(30 \mu \mathrm{g})\end{array}$ & $\begin{array}{l}\text { tetracycline } \\
(30 \mu \mathrm{g})\end{array}$ & $\begin{array}{l}\text { streptomycin } \\
(10 \mu \mathrm{g})\end{array}$ & $\begin{array}{l}\text { cipr } \\
(5 \mu !\end{array}$ \\
\hline F1 & I & $\mathrm{R}$ & $S$ & $\mathrm{R}$ & I & $\mathrm{R}$ & S & $S$ & S & I \\
\hline $\mathrm{F} 2$ & $\mathrm{R}$ & I & $\mathrm{R}$ & I & I & I & S & S & $\mathrm{R}$ & $\mathrm{R}$ \\
\hline F3 & $S$ & $S$ & $S$ & $S$ & $S$ & $S$ & S & $S$ & $S$ & $S$ \\
\hline F4 & $S$ & $\mathrm{R}$ & I & I & $\mathrm{R}$ & $\mathrm{R}$ & $\mathrm{R}$ & I & $\mathrm{R}$ & I \\
\hline F5 & $S$ & I & $S$ & $\mathrm{R}$ & $\mathrm{R}$ & $\mathrm{R}$ & $S$ & $S$ & I & $\mathrm{R}$ \\
\hline F6 & $S$ & $\mathrm{R}$ & $S$ & I & $\mathrm{R}$ & $\mathrm{R}$ & $S$ & I & $\mathrm{R}$ & I \\
\hline F7 & $S$ & $S$ & $S$ & $S$ & $S$ & $S$ & $S$ & $S$ & S & $S$ \\
\hline F8 & $S$ & $\mathrm{R}$ & $S$ & $\mathrm{R}$ & $S$ & 1 & $S$ & $S$ & I & $\mathrm{R}$ \\
\hline F9 & $S$ & I & $S$ & $\mathrm{R}$ & $\mathrm{R}$ & $\mathrm{R}$ & S & S & $\mathrm{R}$ & I \\
\hline F10 & $S$ & $S$ & $S$ & $S$ & $\mathrm{R}$ & $S$ & $S$ & S & $\mathrm{R}$ & $\mathrm{R}$ \\
\hline F11 & $\mathrm{R}$ & $\mathrm{R}$ & 1 & $\mathrm{R}$ & $\mathrm{R}$ & $\mathrm{R}$ & S & S & I & $\mathrm{R}$ \\
\hline F12 & $S$ & $S$ & $S$ & $S$ & $S$ & $S$ & $S$ & S & $S$ & $S$ \\
\hline F13 & $S$ & $\mathrm{R}$ & $S$ & $S$ & $\mathrm{R}$ & $\mathrm{R}$ & $S$ & S & $\mathrm{R}$ & $\mathrm{R}$ \\
\hline F14 & $S$ & I & $S$ & $\mathrm{R}$ & $\mathrm{R}$ & $\mathrm{R}$ & $S$ & $S$ & I & $\mathrm{R}$ \\
\hline F15 & $S$ & $S$ & $S$ & $S$ & $S$ & $S$ & $S$ & $S$ & $S$ & $S$ \\
\hline F16 & I & $\mathrm{R}$ & $S$ & $\mathrm{R}$ & I & $\mathrm{R}$ & $S$ & $S$ & $\mathrm{R}$ & $\mathrm{R}$ \\
\hline F17 & $S$ & I & $\mathrm{R}$ & $\mathrm{R}$ & $\mathrm{R}$ & $\mathrm{R}$ & $S$ & I & $S$ & $\mathrm{R}$ \\
\hline F18 & $\mathrm{R}$ & $\mathrm{R}$ & $\mathrm{R}$ & $\mathrm{R}$ & $\mathrm{R}$ & $\mathrm{R}$ & $\mathrm{R}$ & $\mathrm{R}$ & $\mathrm{R}$ & $\mathrm{R}$ \\
\hline F19 & $S$ & $\mathrm{R}$ & $S$ & $S$ & $\mathrm{R}$ & $S$ & S & $S$ & I & $\mathrm{R}$ \\
\hline
\end{tabular}

I: intermediate susceptibility (zone diameter 12.5-17.4 mm); R: resistant (zone diameter <12.4 mm); S: susceptible (zone diameter >17.5).

Due to technical limitations, table 3 is only available as a download in the Supplemental Files section.

Figures

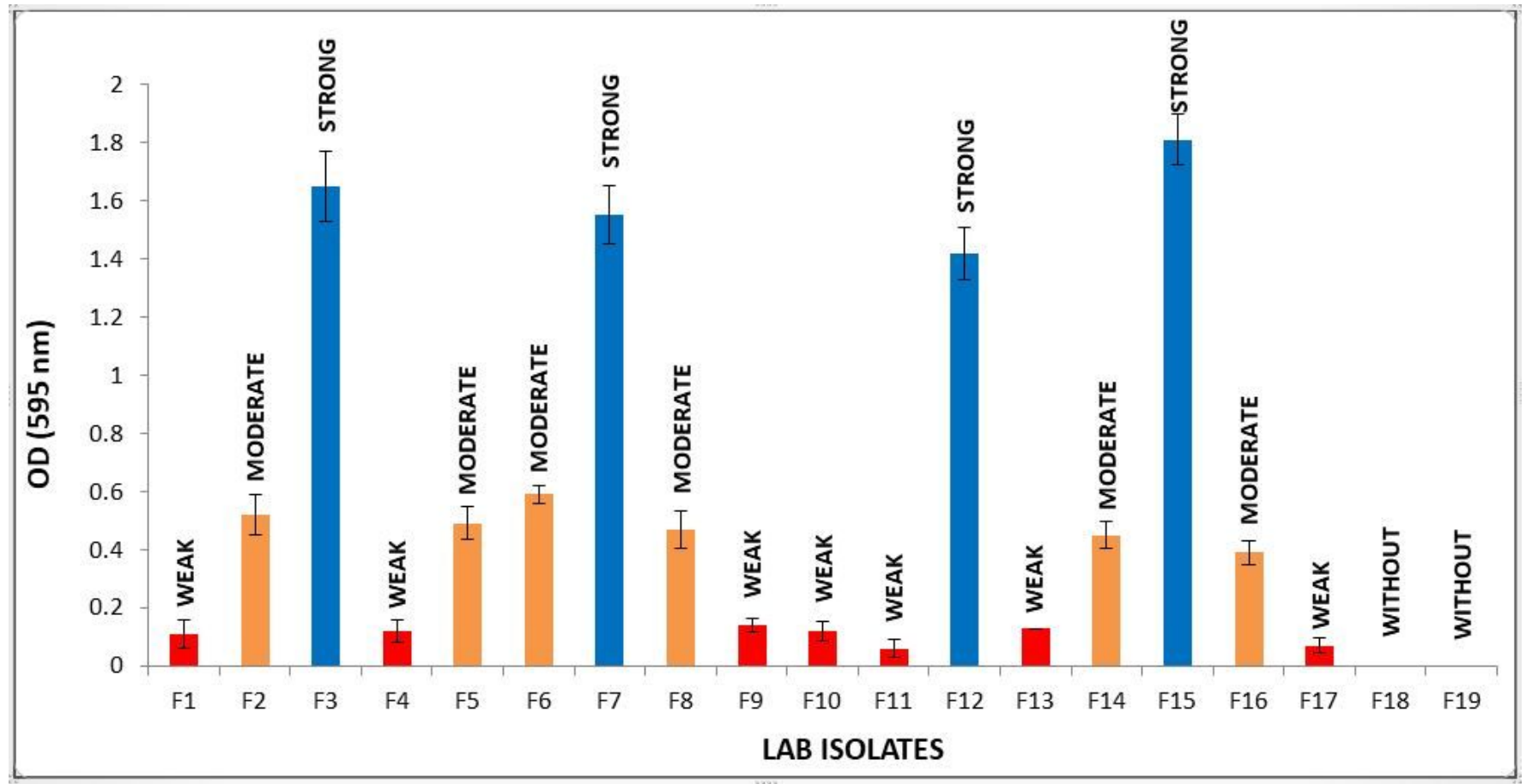

Page 9/11 


\section{Figure 1}

Biofilm formation ability of selected strains. Bars represent standard errors of the mean $(n=3)$. Based on the OD, bacteria were classified as non-biofilm producers $(O D \leq O D C)$, weak $(O D C<O D \leq 2 \times O D C)$, moderate $(2 \times O D C<O D \leq 4 \times O D C)$ or strong biofilm producers $(4 \times O D C<O D ; B o r g e s$ et al., 2012$)$. Where the cut-off $(O D C)$ was defined as the mean OD value of the negative control

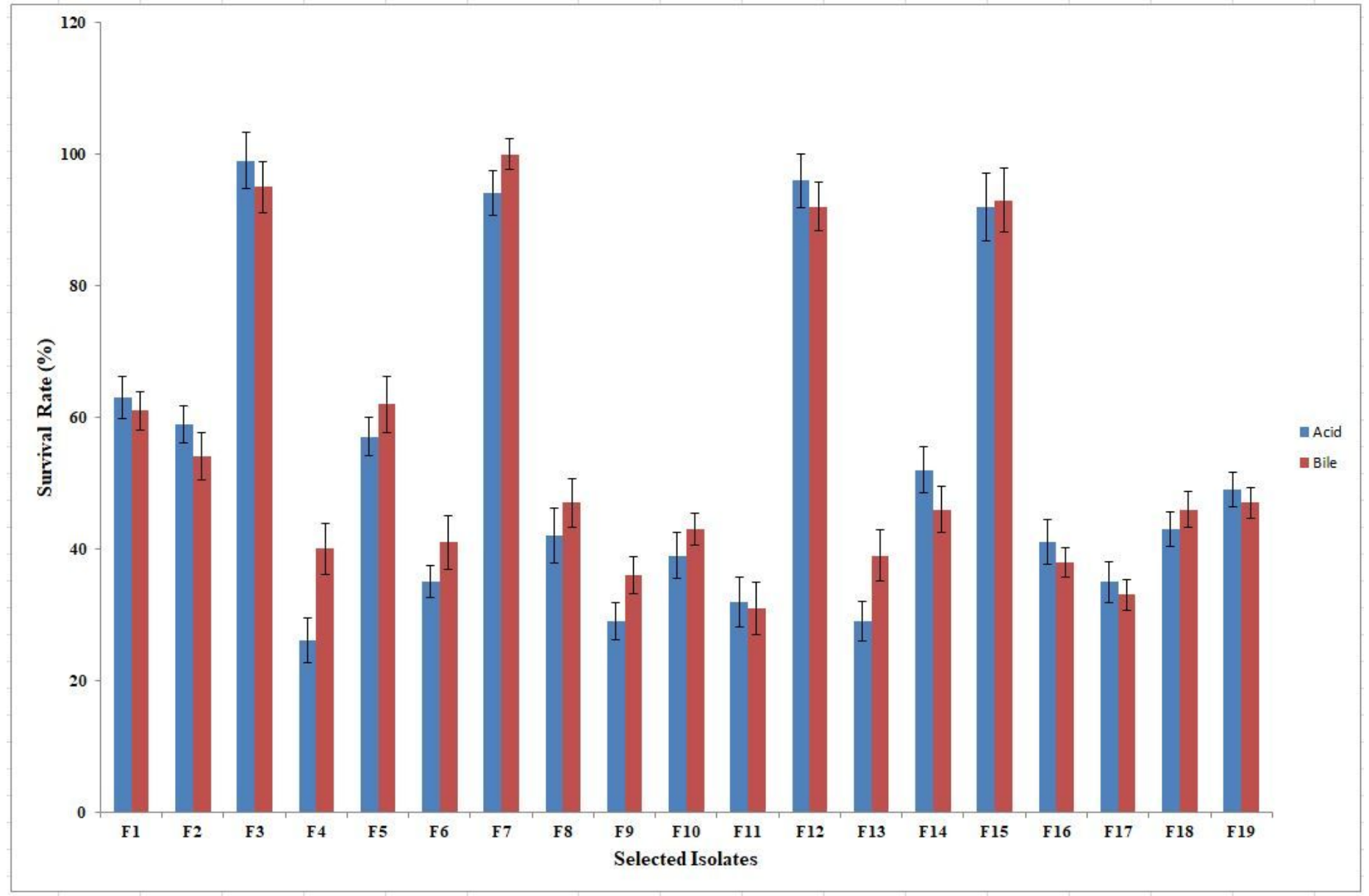

Figure 2

Tolerance of isolates to low $\mathrm{pH}$ and high bile salt concentrations 
A

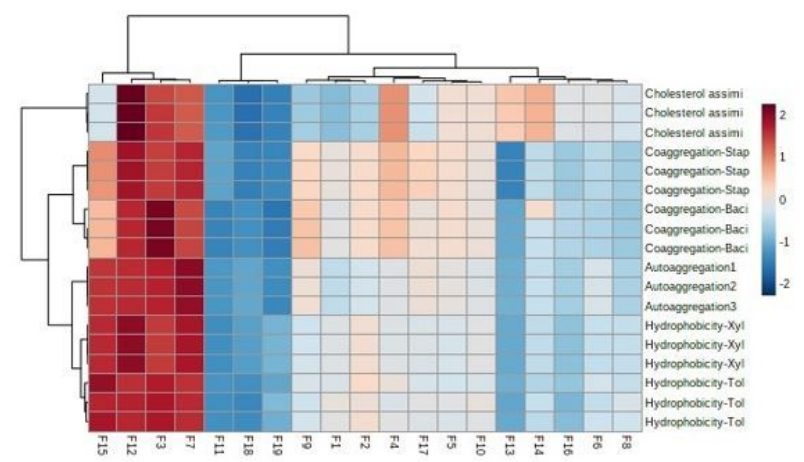

B

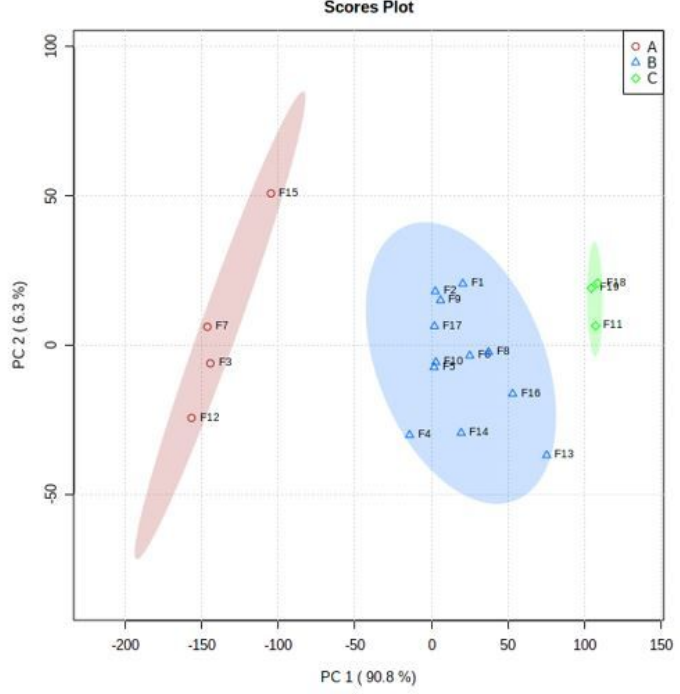

Figure 3

Cluster analysis of isolates based on probiotic characteristics using heat-map (A) and PCA (B) methods.

\section{Supplementary Files}

This is a list of supplementary files associated with this preprint. Click to download.

- Table3.jpg 